\title{
The Pharmaceutical Year That Was, 2014
}

\author{
Anthony W. Fox
}

Published online: 22 November 2014

(c) Springer International Publishing Switzerland 2014

Last year ended with Europe still wallowing in its Eurocrisis, the promise of a Pharmacovigilance Risk Assessment Committee (PRAC) getting into its stride, and the great 'EMA will be giving away your data' controversy [1].

One useful thing that PRAC has started doing is announcing the safety signals that it is interested in. This is particularly valuable because such signals may transcend pharmacological class of drug, and rare hazards may only be identifiable with data drawn from multiple products and manufacturers. At about 17 pages each month, the PRAC agenda is an intimidating document. One wonders whether a more efficient system of sub-committees could be devised.

As for the EMA transparency initiative, the publication of data process has come to resemble a Freedom of Information request process. The requester applies to EMA, who then notifies the clinical trial sponsor or Marketing Authorization applicant which documents are involved. The permitted redactions are very narrow: mostly restricted to information that could lead to the identification of a patient, and some junior company employees. However, the names of those who are responsible for each aspect of the study in the sponsor's organisation cannot be redacted, and neither can the identities of principal and associate clinical investigators.

A.W. Fox is the Consulting Editor for Pharmaceutical Medicine.

\section{A. W. Fox $(\square)$}

Faculty of Life Sciences and Medicine, Pharmaceutical Medicine Group, Institute of Pharmaceutical Sciences, Academic Centre, Room 3.52 Franklin-Wilkins Building, King's College London, 150 Stamford Street,

London SW10 1LH, UK

e-mail: Tony.Fox@kcl.ac.uk
However, the EMA has a selective view of transparency [2]. While happy enough to distribute other peoples' data, the EMA does not share the identity of the requester with the study or application sponsor. The volume of requests has also not been published (one or two pharmacovigilance specialists in different companies describe receiving requests at up to weekly frequency; personal communication). Since risk management plans are also now required in a template that is publication-ready, it is a reasonable presumption that these are popular publications. The EMA have not made any attempt to assess the impact of publishing all these data; since the destination and quantity of publication is unknown (except to the EMA), there cannot be any independent assessment of whether any harm or benefit, is happening. That's doubtless the way the EMA wants it.

Pfizer's failed flirt with AstraZeneca must be the large pharma event of the year. Three or four priced offers became public knowledge, although the deal structures (e.g., cash/stock components, etc.) were often unclear. Amusingly, the proffered rationale for the transaction evolved within a period of several weeks. Initially, it was to support the Pfizer drug development pipeline. The R\&D going on at AstraZeneca was a great compliment. Then people noticed Pfizer's large cash stockpile, and an acquisition favoured paying less corporation tax in the USA. It then turned out that cash stockpile was not in the USA at all, but in various low-tax paradise islands. With the newspapers' opinions declining, Pfizer then stated that post-merger it would move its headquarters to the UK, and become a British company. That remarkable offer was promptly termed a 'tax inversion'. So, then the politicians got involved. If they had been angling in the back rooms before, the politicians on both sides of the Atlantic now came out against Pfizer in public. On May 14, 2014, the 
British Prime Minister (PM) was questioned in the House of Commons. It turned out that he had had secret meetings with Pfizer. The Leader of the Opposition taunted the PM with the fact that he had not met with AstraZeneca, and that Pfizer did not need a public relations officer because they had already got one in the PM. The PM claimed he had been seeking guarantees about 'British jobs, investment and science', which rang a bit hollow because the last time the unmedicated honourable members of the House of Commons had heard of Pfizer was when the company sold its Discovery Centre at Sandwich (Kent, UK), in 2012.

But AstraZeneca was not to be wooed, and that was what, in the end, saved the politicians' blushes. AstraZeneca rebuffed every offer, and as the motives of Pfizer seemed to evolve, then so the business community's empathy with AstraZeneca seemed to increase. In the UK, hostile takeovers must be completed within a certain period of time. The Pursuer can then make a final offer, and, if successfully rejected, then the pursued is entitled to 6 months respite from the pursuer, in order to operate its usual business. Those 6 months expired in November 2014, and Pfizer has not indicated any further interest. Meanwhile, AstraZeneca looks like it will close the year in very healthy financial condition [3], and it has broken ground on its new R\&D centre in Cambridge (Cambridgeshire, UK) [4]. The US Congress, fearing a systematic loss of revenues due to 'tax inversion', not only from Pfizer but also other companies, is now drafting legislation to imprison US companies in the USA. Meanwhile, without legislation, the US Treasury has been quicker off the mark with new regulations under five sections of the tax code to make 'tax inversions' more difficult [5].

June saw 'OpenAccess' rolled out by FDA [6]. This is an initial 'Three million adverse events at your fingertips' database with a useful search engine. Another effort towards transparency, these are aggregated databases held by FDA that have now been made available to the public. This is a reasoned approach to transparency that will doubtless help the pharmacovigilance and public health communities. The cherry-picking lawyers will doubtless try to exploit it, but at least their opponents will have an equivalent access to the data.

The cannabis issue rumbles along. During the year a few US states have 'legalised' it, meaning that possession of about an ounce of the vegetable is all right. Two 'little old ladies' have appeared in the UK newspapers during the year having grown it: tipping out the budgerigar's sand paper cage floor onto the compost heap usually does the trick. This is the reason why the possession of cannabis seed (a component of a famous cage bird food that makes 'em sing better) is quite legal in the UK. Cannabinol tablets, albeit highly regulated, have long been prescribable in many jurisdictions. So the whole thing might boil down to the rapid absorption pharmacokinetics of inhalation, not the possession of the substance itself. Meanwhile, no UK national or US federal politician is going out on a limb for Johnny's joints.

For those medically- or dentally-qualified and working in the industry in the UK, we have now had a complete year of appraisal and revalidation. First, the doctor or dentists must affiliate with a Designated Body (DB). Then he or she must construct a portfolio of documents that represent his or her practice, write reflective notes on each document, and meet and discuss these with a trained and approved (by the DB) appraiser. There must also be a $360^{\circ}$ feedback tool, and any clinical work has to be supported with 30 patient feedbacks. The DB-approved appraiser then makes a recommendation to the Responsible Officer (RO) of the DB. The RO, in turn recommends to the General Medical Council (GMC) whether the doctor or dentist remains fit to practice. The GMC then decides whether to award the doctor or dentist a licence to practice for another 5 years (when the whole process will have to be repeated). This ludicrous, bureaucratic process is unique to the UK; we can't even blame some, stupid EU directive! In response, some of the large pharmaceutical companies have declared themselves to be DBs, and they revalidate their own doctors and dentists (the conflict of interest aspects of this are ignored). The biggest problem is that the whole system has been designed around the routine processes of clinicians in the National Health Service. Pharmaceutical physicians and dental surgeons are something of a square peg in a round hole, as are pathologists, occupational health physicians and others; the Faculty of Pharmaceutical Medicine at least got us exemption from the 30 patients' feedback. The financial cost of this process is borne by the revalidating doctor or dentist him or herself; arguably tax-deductible, it costs about $£ 900$ per annum, depending on the DB. The DBs are rapidly growing their own bureaucracy, by developing databases of mugshots of the doctors they oversee, holding mandatory meetings for appraisers to remain approved, hiring teams of 'appraisal leads' to perform quality assurance with complete access to supposedly confidential databases, and generally thinking up additional bells and whistles that consume time and justify an increase in staffing and price. Meanwhile, the professional organisations have been passive: most of the doctors working for the British Medical Association have simply resigned their licences rather than trying to comply with a bureaucracy that is incompatible with their professional work.

So what might 2015 bring? The European Union is still in a fragile economic situation. The economic recovery in the USA, as noticed in last year's summary, is now wellestablished. The UK is somewhere in between: doing well compared with Europe, but lagging the USA. At this point, the UK general election (May 2015) is very unpredictable; polls are fluctuating and there is a new political party on 
the scene. The US dollar is strong, the Euro is weak, and the central bankers of the latter think that the strongest members of the European Union will continue to prop it up, a recent bill to the UK for 1.7 billion euros over and above the usual annual contribution is based on the relative economic strength of the country; it does not help the proEuropean bureaucrats politically. The US mid-term elections mean that its President is now opposed by both houses of Congress, rather than just the one as before; however, given the effectiveness of the obstruction by one house of Congress in recent years, the slow pace of legislation in the USA is not likely to accelerate during the next 2 years.

On the regulatory front, the FDA is still struggling with how to regulate biosimilars. In July, some legal action was commenced against the EMA's release of data to all who ask for it, although that has now gone very quiet; expectation: no change likely. EMA fees will rise again during the year, as that bureaucracy grows without any improvement in its efficiency. The politicians see the pharmaceutical industry as a bank: they've got the money and all we need to do is invent new ways to take it from them. It is just possible that next year will see the start of a new generation of pharmacovigilance reporting which exploits the nowpublic FDA databases in new ways. Anti-viral therapies face paradigm change: the AIDS community now realises that HIV infection is a non-lethal chronic disease, and how should it be managed by general practitioners? The hepatitis $\mathrm{C}$ community can be pleased that new oral therapies are available, and long-term may see that disease eradicated completely. Lastly, there are also signs that the US investment community is opening the window; 2015 could be a good year for small biotech companies to find funding in the USA.

Happy New Year!

Acknowledgements Dr. Fox is the Consulting Editor of Pharmaceutical Medicine. He has no other conflicts of interest to declare. There was no financial support for this Editorial.

\section{References}

1. Fox AW. The pharmaceutical year that was, 2013. Pharm Med. 2013;27:339-94.

2. European Medicines Agency. Transparency (online). http://www. ema.europa.eu/ema/index.jsp?curl=pages/special_topics/general/ general_content_000526.jsp\&mid=WC0b01ac0580789730. Accessed 7 Nov 2014

3. Roland D. Astra issues second upbeat forecast in three months. Daily Telegraph November 7. 2014. p. B5.

4. Personal observation from Cambridge-London railway train November 1. 2014.

5. McKinnon JD, Paletta D. Obama Administration Issues New Rules to Combat Tax Inversions: Actions Intended to Make Inversions Harder to Accomplish, Less Profitable (online). Wall Street Journal 2014. http://online.wsj.com/articles/treasury-to-unveilmeasures-to-combat-tax-inversions-1411421056. Accessed 7 Nov 2014.

6. Tyer D. FDA begins data initiative with millions of adverse event reports (online). PMLiVE 2014. http://www.pmlive.com/blogs/ digital_intelligence/archive/2014/june/fda_releases_millions_of_ adverse_event_reports_to_begin_open_data_initiative. Accessed June 42014. 